\title{
First Annual Report of the Resident Committee of the American College of Radiation Oncology
}

\author{
Jonathan W. Lischalk ${ }^{1} \cdot$ Karna Sura $^{2}$ - Michael C. Repka ${ }^{1}$ - Jonathan E. Leeman ${ }^{3}$.

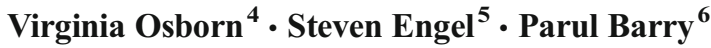

Received: 27 June 2017 / Accepted: 9 October 2017 /Published online: 24 October 2017

(C) Springer-Verlag GmbH Germany 2017

\section{Introduction}

The American College of Radiation Oncology (ACRO) Resident Committee (RC) was established to provide meaningful educational content, professional development, and opportunities for service within the United States radiation oncology resident community. The goals of the $\mathrm{RC}$ mirror those of the ACRO mission at large to "promote success in the practice of radiation oncology through education, responsible socioeconomic advocacy, and integration of science and technology into clinical practice." The ACRO Board of Chancellors has given marked independence to the ACRO RC to explore and implement a resident-focused agenda, which has allowed great ideas to flourish into full-fledged national programs. The RC has worked diligently

J.W.L and K.S. contributed equally to this work and should be regarded as co-first authors.

\section{Jonathan W. Lischalk}

jonathan.lischalk@gunet.georgetown.edu

1 Department of Radiation Medicine, Georgetown University Hospital, Washington, DC, USA

2 Department of Radiation Oncology, Beaumont Health, Royal Oak, MI, USA

3 Department of Radiation Oncology, Memorial Sloan Kettering Cancer Center, New York, NY, USA

4 Department of Radiation Oncology, SUNY Downstate Medical Center, Brooklyn, NY, USA

5 Department of Radiation Oncology, University of Miami, Miami, FL, USA

6 Department of Radiation Oncology, Rush University Medical Center, Chicago, IL, USA to improve resident quality of life and education through the creation and implementation of distinct subcommittees within the RC, which include the following: membership, mentorship, research, scholarship, and scientific. Over the past year, the ACRO RC has developed and implemented a variety of projects; here, we report the results of the 2016-2017 academic year.

\section{Membership}

As of February 2017, the ACRO community includes the largest total number of registered resident members since the inception of resident-specific membership. Considering all radiation oncology residents nationwide, nearly half are registered ACRO members. Undoubtedly, much of this increase can be attributed to the wide array of ACROsponsored scholarships and webinars, described in more detail below. To promote early engagement with the ACRO community, the RC has successfully expanded membership to include PGY-1 level residents who have matched into radiation oncology, as well as fourth-year medical students applying to the specialty. With resident members comprising nearly one third of the entire ACRO organization, we believe this group represents the single largest opportunity for growth within the College. Each year, more than 150 residents graduate and embark on their radiation oncology careers as new attending physicians. Through the promotion of early involvement and engagement with the ACRO organization as residents, we believe these members will be poised to maintain their relationship with the College as new practitioners. To enhance this transition, the $\mathrm{RC}$ is in the process of improving coordination with the ACRO New Practitioner Committee. 


\section{Mentorship}

A study by Dhami et al. found an unmet need for mentorship in radiation oncology training programs with approximately $75 \%$ of polled residents expressing desire for a formal mentorship experience [1]. The ACRO RC has developed a program that connects attending mentors from a wide range of radiation oncology practices and site specialties with residents in training. This program aims to foster in-person meetings at annual radiation oncology conferences to facilitate career development and create lasting relationships. Mentors and mentees have been connected at the annual ASTRO and ACRO meetings using a tailored survey system to match participants using a variety of metrics. The evolution of this mentorship program has illuminated the importance of resident networking beyond the home institution. To our knowledge, this is the only individually tailored mentorship program sponsored by a national professional society. At the American Society for Radiation Oncology (ASTRO) 2016 annual meeting, we received 75 requests by residents for faculty mentors. In addition, similar strong interest was seen for the program at the annual ACRO meeting in 2017. We believe this experience will translate into long-term relationships beneficial to both parties.

A notable lack of formal mentorship is prevalent in the medical student population [2]. Given the difficulty of matching into radiation oncology in the United States, advice regarding the development of a successful curriculum vitae and an understanding of the application and interview process is critical. We have therefore initiated a mentorship program partnering medical student mentees with ACRO resident mentors. We believe residents who have just completed the taxing process of applying and matching into radiation oncology serve as optimal mentors and offer meaningful advice for students interested in the field, particularly those without an institutional residency program.

\section{Scholarship}

The ACRO RC scholarship program has seen substantial expansion over the past two years (Table 1). The vision of the committee is to create two broad categories of scholarship opportunities to support (1) academic research and (2) international electives. The academic research scholarship opportunities are subdivided into the following: (1) clinical, translational, and basic science research supported by the ACRO RC Seed Grant, and (2) resident and medical student educational research supported by the ACRO RC Educational Grant. The international elective scholarship opportunities are also subdivided into the following: (1) international underserved opportunities supported by the ACRO RC Global Radiation Oncology Workforce (GROW) Scholarships, and (2) international radiation oncology experience in Germany and stateof-the-art particle therapy training supported by the ACRO RC
Heidelberg Ion Therapy Scholarships. A complete list of scholarship winners with correspopnding project titles over the past few years can be seen in Table 1 .

In an era of dwindling scientific grants, the ACRO RC affirms the importance of resident-led clinical, translational, and basic science research by providing the yearly ACRO RC Seed Grant. The Seed Grant was created as initial funding for talented resident projects including "Use of PET/CT-based radiomic features for clinical outcome prediction in patients with limited stage small cell lung cancer," and "PIK3 mutation association with increased local failure in patients with brain metastases treated with stereotactic radiation" [3]. The grant recipients are then invited to present the results of their cutting-edge work either in abstract or in presentation format at the subsequent ACRO annual meeting.

The ACRO RC Educational Grants have successfully subsidized unique resident and medical student educational research driven by motivated radiation oncology residents. The spirit of this grant is to support resident-led research into improvements in resident and medical student education. For example, the popular new online contouring atlas eContour. org was created in part with Educational Grant funding. More recently, Shaverdian et al. published a study that used ACRO Educational Grant money to explore national gaps in radiation oncology awareness in the wider medical community [4]. Ongoing projects subsidized by the educational grant include "Assessing residency expansion and job placement issues in radiation oncology through an all-encompassing survey" and "Proficiency based cervical brachytherapy simulation training."

The ACRO RC Heidelberg Ion Therapy Scholarships have provided funding for a 1-month rotation at the Heidelberg Ion Therapy Center (HIT) in Germany, an opportunity to gain experience with heavy ion treatment at one of only a handful of centers in the world where this modality is available. This scholarship is an excellent example of the rapidity with which innovative and exciting ideas can be developed and implemented by the ACRO RC; within months of the idea's inception the funding support was approved by the ACRO board and the first grant recipient rotated at HIT later that year. HIT scholarship winners have rotated for one or more months in Heidelberg, Germany, where they gained international radiation oncology experience and state-of-the-art particle therapy training. These residents have gone on to describe their experience at multiple meetings including the ACRO annual meetings and have also published collaborative manuscripts [5].

The ACRO RC has developed a relationship with Radiating Hope, an organization which works to increase access to radiation oncology equipment in underserved areas. Through the GROW Scholarship, recipients have received funding to attend the Greater Horn Oncology Symposium in conjunction with a climb of Mt. Kilimanjaro. Residents have also received funding 
Table 1 List of ACRO RC scholarship winners

\begin{tabular}{|c|c|c|}
\hline Scholarship & Winner & Project \\
\hline \multirow[t]{4}{*}{ Seed Grant } & 2016 Benjamin Lok, M.D. & $\begin{array}{l}\text { Utilizing a }\left[{ }^{18} \mathrm{~F}\right] \mathrm{PARPi} \text { PET radiotracer as a real-time in vivo } \\
\text { pharmacodynamic biomarker of an orally administered } \\
\text { PARP inhibitor }\end{array}$ \\
\hline & 2016 Sophia Kamran, M.D. & $\begin{array}{l}\text { Use of PET/CT-based radiomic features for clinical outcome } \\
\text { prediction in patients with Limited Stage Small Cell } \\
\text { Lung Cancer }\end{array}$ \\
\hline & 2015 Natalie Lockney, M.D. & $\begin{array}{l}\text { PIK3 mutations are associated with increased local failure in } \\
\text { patients with brain metastases treated with stereotactic } \\
\text { radiation }\end{array}$ \\
\hline & 2015 Anthony Wong, M.D., PhD. & $\begin{array}{l}0 \text { vs. } 2 \mathrm{~mm} \text { margins in frameless stereotactic radiosurgery for } \\
\text { intact brain metastases: study protocol for a randomized } \\
\text { trial }\end{array}$ \\
\hline \multirow[t]{4}{*}{ Educational Grant } & 2016 Karna Sura, M.D. & $\begin{array}{l}\text { Assessing residency expansion and job placement issues in } \\
\text { Radiation Oncology through all-encompassing survey }\end{array}$ \\
\hline & 2016 Sherry Zhao, M.D. & Proficiency-based cervical brachytherapy simulation training \\
\hline & 2015 Narek Shaverdian, M.D. & $\begin{array}{l}\text { Gaps in radiation therapy awareness: Results from an } \\
\text { educational multi-institutional survey of United States } \\
\text { internal medicine residents }\end{array}$ \\
\hline & 2015 Erin Gillespie, M.D. & www.eContour.org \\
\hline \multirow[t]{4}{*}{ HIT Scholarship } & 2016 William Arscott, M.D. & Heidelberg International Rotation \\
\hline & 2016 Samuel Marcrom, M.D. & Heidelberg International Rotation \\
\hline & 2015 Michael Repka, M.D. & Heidelberg International Rotation \\
\hline & 2015 Vivek Virma, M.D. & Heidelberg International Rotation \\
\hline \multirow[t]{8}{*}{ GROW Scholarship } & 2017 Serguei Castaneda & Radiating Hope trip to Everest Base Camp \\
\hline & 2017 Lindsay Puckett & Clinical rotation in Botswana \\
\hline & 2016 Shefali Gajjar, M.D. & Greater Horn Oncology Symposium and Kilimanjaro Climb \\
\hline & 2016 Chika Nwachukwu, M.D., PhD. & Greater Horn Oncology Symposium and Kilimanjaro Climb \\
\hline & 2016 Adam Olson, M.D. & Greater Horn Oncology Symposium and Kilimanjaro Climb \\
\hline & 2015 Sanjay Maraboyina, M.D. & Radiating Hope trip to Ghana \\
\hline & 2015 Debra Yeboa, M.D. & Radiating Hope trip to Ghana \\
\hline & 2015 Michael Scott, M.D. & Radiating Hope trip to Ghana \\
\hline
\end{tabular}

to be used towards other global experiences including in Botswana and Tanzania.

\section{Webinars}

Over the past year, the committee has sought to expand educational and mentorship opportunities via online webinar sessions. This educational modality has allowed an economical approach for outreach to a wide audience and allows for real-time question-answer sessions. The focus of these webinar sessions fell into two broad categories: (1) clinical areas of ambiguity or heterogeneity in radiation oncology, and (2) career advice and counseling. An outline of the webinar schedule can be seen in Table 2 .

The first webinar of the 2016-2017 academic year was aimed at assisting medical students who were preparing to apply for radiation oncology residency. In producing this webinar, we identified the aforementioned lack of mentorship in this population, which was highlighted in a subsequent publication [2]. Our webinar series then transitioned to a resident career-specific focus with a special panel exploring residency and fellowship expansion as well as a session focused on the management of student loans and the general financial well-being of the resident.

Our focus then shifted to the scientific program, which was highlighted by a contouring webinar series exploring three complex topics: head and neck cancer, spine SBRT, and gynecological cancer. Three radiation oncology experts were identified and agreed to give lectures on the aforementioned subjects, and in addition, most webinar participants agreed to partake in a survey related to the contouring education experience at their home institutions. We recently published the results of surveys associated with this contouring series where we found heterogeneity in residency education and discovered multiple areas of improvement including evaluating image-guided radiation 
Table 2 Schedule of ACRO RC webinars for the 2016-2017 year

\begin{tabular}{|c|c|c|}
\hline Date & Title of webinar & Presenter \\
\hline July 25,2016 & Applying to Radiation Oncology: A Program Director's Perspective & Dr. Neha Vapiwala \\
\hline August 4, 2016 & Ins and Outs of Negotiating a Private Practice Job & Dr. Paul E. Wallner \\
\hline August 25, 2016 & Residency Expansion: Facts and Myths & $\begin{array}{l}\text { Drs. Craig Stevens, Benjamin Falit, } \\
\text { Hubert Pan, and Karna Sura }\end{array}$ \\
\hline September 7, 2016 & $\begin{array}{l}\text { Learning How to Get What You Need to Succeed: Negotiating } \\
\text { an Academic Job }\end{array}$ & Dr. Reshma Jagsi \\
\hline November 7, 2016 & 3D Image-based Brachytherapy for Cervical Cancer & Dr. Sushil Beriwal \\
\hline November 14, 2016 & An Overview Selecting and Planning Spinal SBRT & Dr. Amol Ghia \\
\hline November 28, 2016 & Contouring for Head and Neck Cancer & Dr. Sue Yom \\
\hline December 20, 2016 & Are You Buried? Managing Your Medical School Student Loan Debt & Jeff Witz \\
\hline
\end{tabular}

therapy (IGRT) and interpreting magnetic resonance imaging (MRI) [6].

\section{ACRO annual meeting}

The ACRO annual meeting offers a resident-specific symposium developed by the RC, which features renowned attendings in our field. The program offers formal lectures and gives participants the opportunity to ask questions and interact directly with the speakers in an informal setting. The intimate interaction of chairpersons and attendings with the resident community has been a consistently well-received by the resident participants. Past speakers have included Drs. Julia White, Arno Mundt, Steven Finkelstein, Lawrence Kleinberg, Lawrence Marks, and Larry Kestin. The symposium also offers an overview of billing and coding, which are essential to independent practice yet often overlooked by many training programs. Each year, the RC scientific subcommittee chairman has sat on the ACRO scientific committee and has participated in abstract selection and the scientific direction of the program. We have also developed a Joblink mock interview program, which links senior residents with attendings to practice interviewing skills and review CVs prior to initiating the job application process.

Each year, the RC sends a representative to the American Medical Association (AMA) as a delegate representative to the Resident and Fellow Section assembly. Given the small size of our specialty, it is critical we remain active participants and a strong voice in the medical community for our patients, profession, and specialty. The annual AMA conference is an opportunity for radiation oncology residents to make their voices heard including on issues such as the oncology Cancer Moonshot, oncology medical home, and residency/ fellowship expansion.

\section{Future direction}

Over the coming years, we would like to develop a stronger mentorship program with more mentor-mentee pairs, as this appears to be an area of need within the greater resident and medical student community. We hope to bolster the long-term stability of these pairs and focus on developing lasting relationships among the participants. As membership rates have tended to decline as residents graduate, the RC will also collaborate with the New Practitioner Committee to strategize methods for maintaining member engagement during the transition from residency to practice.

Furthermore, we are developing multiple programs for improving medical student involvement in ACRO. We now offer a medical student-specific mentorship program, which will be further implemented at ASTRO 2017. Building on last year's success, we are developing new webinars including one focused on medical student away rotations in radiation oncology; as with our first webinar, we hope to alleviate some of the stress associated with radiation oncology application. Finally, given deficiencies identified during last year's contouring series, future interactive webinars will focus on IGRT implementation and MRI evaluation.

We have expanded our scholarships to include a grant specifically for rotations in underserved areas across the globe. The scholarship would not only provide funding but also create a streamlined program infrastructure. We are currently developing specific rotation locations around the world. We believe future radiation oncology residents will take advantage of this grant to improve radiation oncology care and to develop an awareness and understanding of global oncologic issues.

Finally, a focal point of the coming year will be addressing the lack of minority involvement in radiation oncology, 
which was has been described by both Barry et al. and Knoll $[7,8]$. We are currently developing programs to better understand barriers in radiation oncology for women and are in the process of creating an entirely new ACRO RC subcommittee dedicated to expanded outreach in radiation oncology.

Acknowledgements James Leckie contributed administrative support for the implementation of resident committee programs. The ACRO Board of Chancellors supported the implementation of resident committee programs.

Author's contributions All authors contributed to the drafting of this manuscript and implementation of specific designated programs throughout the 2016-2017 academic year. All authors contributed to revising and giving final approval to the submitted manuscript. All authors agree to be accountable for all aspects of the work including its accuracy and integrity.

Funding Information No funding support is associated with this study.

\section{Compliance with ethical standards}

Conflict of interests The authors declare that they have no conflict of interest.

Ethical approval This article does not contain any studies with human participants or animals performed by any of the authors.

Informed consent Statement of informed consent was not applicable since the manuscript does not contain any patient data.

\section{References}

1. Dhami G, Gao W, Gensheimer MF, Trister AD, Kane G, Zeng J Mentorship programs in radiation oncology residency training programs: a critical unmet need. Int J Radiat Oncol Biol Phys 94(1):2730. https://doi.org/10.1016/j.ijrobp.2015.09.021

2. Sura K, Lischalk JW, Leckie J, Grills IS, Vapiwala N Applying for radiation oncology residency: webinar-based medical student mentorship outreach. Int J Radiat Oncol Biol Phys 97(1):11-12. https:// doi.org/10.1016/j.ijrobp.2016.09.024

3. THE PROCEEDINGS OF ACRO 2017 (2017) J Radiat Oncolo:121. https://doi.org/10.1007/s13566-017-0316-5

4. Shaverdian N, Yoo SM, Cook R, Chang EM, Jiang N, Yuan Y, Sandler K, Steinberg M, Lee P Gaps in radiation therapy awareness: results from an educational multi-institutional survey of United States internal medicine residents. Int J Radiat Oncol Biol Phys. https://doi.org/10.1016/j.ijrobp.2017.03.028

5. Lischalk JW, König L, Repka MC, Uhl M, Dritschilo A, Herfarth K, Debus J From Roengten rays to carbon ion therapy: the evolution of modern radiation oncology in Germany. Int J Radiat Oncol Biol Phys 96(4):729-735. https://doi.org/10.1016/j.ijrobp.2016.08.026

6. Sura K, Lischalk JW, Leckie J, Welsh JS, Mundt AJ, Fernandez E Webinar-based contouring education for residents. J Am Coll Radiol. https://doi.org/10.1016/j.jacr.2017.03.013

7. Knoll MA Defining and shattering the glass ceiling in radiation oncology. Int J Radiat Oncol Biol Phys. https://doi.org/10.1016/j. ijrobp.2017.03.027

8. Barry PN, Miller KH, Ziegler C, Hertz R, Hanna N Dragun AE factors affecting gender-based experiences for residents in radiation oncology. Int J Radiat Oncol Biol Phys 95(3):1009-1016. https://doi. org/10.1016/j.ijrobp.2016.02.007 